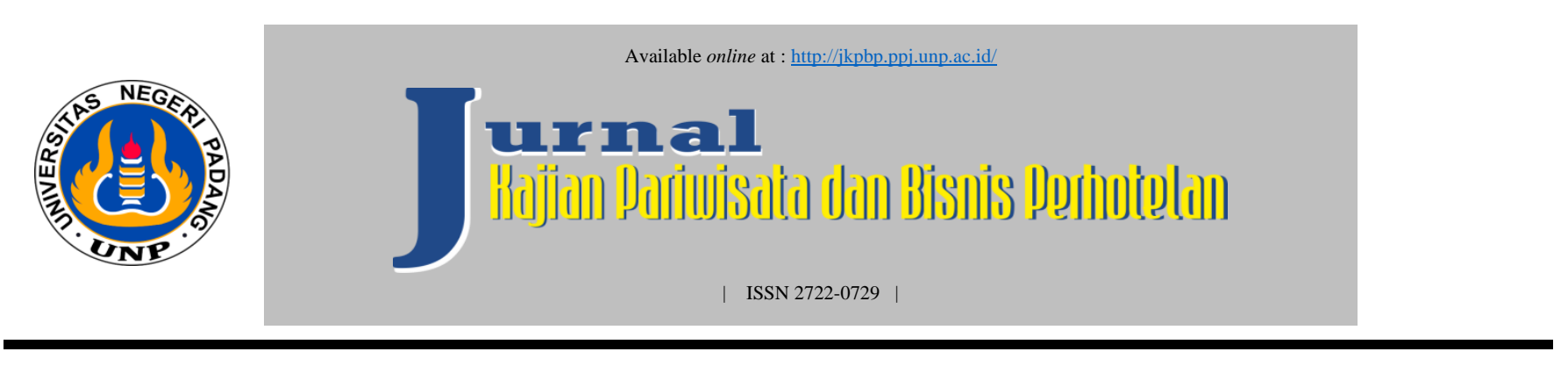

\title{
Pengaruh Store Atmosphere dan Service Quality Terhadap Revisit Intention Konsumen Pada Muaro Terrace Grand Inna Padang
}

\author{
Robbi Yasin ${ }^{1}$, Lise Asnur ${ }^{2}$ \\ ${ }^{1}$ Universitas Negeri Padang 1 \\ ${ }^{2}$ Universitas Negeri Padang 2
}

Corresponding email : Robbiyasin07@gmail.com

\begin{abstract}
Abstrak
Tujuan Penelitian adalah untuk melihat bagaimana pengaruh Atmosphere dan Service Quality Terhadap Revisit Intention pada Muaro Terrace agar dapat meningkatkan kunjungan yang berdampak pada pendapatan Muaro Terrace. Penelitian ini juga untuk mengidentifikasi store atmosphere serta service quality di Muaro Terrace yang berdampak pada revisit intention. Penelitian ini menggunakan jenis data kuantitatif dengan metode asosiatif. Sampel penelitian sebanyak 98 orang pengunjung, yang mengisi angket dengan lima pilihan jawaban. Analisis menggunakan regresi linear berganda yang telah melalui uji prasyarat berupa, uji normalitas, multikoloniearitas dan heteroskedasitas. Pada hasil pengolahan data dari 98 sampel, dengan menggunakan SPSS versi 20.00. Diketahui bahwa variabel Store Atmosphere (X1) secara keseluruhan menunjukan persentase $82,7 \%$ pada rentang $\geq 84$ dengan kategori sangat baik. Variabel Service Quality (X2) secara keseluruhan menunjukan persentase $82,7 \%$ pada rentang $\geq 55,99$ dengan kategori sangat baik. Variabel Revisit Intention (Y) secara keseluruhan menunjukan persentase 52\% pada rentang $\geq 60$ dengan kategori sangat baik. Dari hasil terlihat bahwa uji Regresi linear berganda diperoleh F hitung 19,868 dengan sign $0,000<0,05$ maka variabel (X1 dan X2) berpengaruh signifikan terhadap variabel (Y), maka Ha diterima. Kemudian koefisien determinasi diperoleh $\mathrm{R}$ square 0,295, artinya kontribusi variabel Store Atmosphere dan Service Quality terhadap variabel Revisit Intention sebanyak $29,5 \%$ sedangan $70,5 \%$ ditentukan oleh faktor lain.
\end{abstract}

Kata kunci : Store Atmosphere, Service Quality, Revisit Intention. 


\section{PENDAHULUAN}

Industri Pariwisata yang sangat berkembang pesat saat ini adalah akomodasi penginapan atau yang sering disebut dengan hotel. [1] Selain akomodasi penginapan, industri di bidang food and beverage juga berkembang. Terlihat banyaknya resto, café maupun coffe shop yang tersebar diseluruh Indonesia. [2] Coffee Shop adalah "sebuah tempat yang menyediakan kursi serta meja dengan menjual jenis variasi kopi serta makanan ringan sebagai pendamping diiringi music melodi dan suasana nyaman yang dapat dirasakan oleh konsumen”. Di kota Padang banyak terdapat cafe cafe maupun coffee shop. Salah satu coffee shop di Kota Padang yang telah memiliki izin resmi dari BPMPTSP adalah Muaro Terrace. Muaro Terrace merupakan salah satu coffee shop yang terletak di Jalan Gereja No. 34, Padang Barat, Sumatra Barat. Muaro Terrace adalah salah satu fasilitas hotel yang terbuka untuk umum 24 jam. Cita rasa resto dan cafe ada pada Muaro Terrace dengan suasana nyaman dan mengikuti trend masa kini seperti di lengkapi dengan live music setiap senin sampai sabtu. Menu-menu yang ditawarkan di Muaro Terrace lebih spesifik ke signature coffee, sehingga membuat tamu yang menyukai coffee datang kembali berkunjung.

[3] minat kunjungan ulang adalah "kemungkinan konsumen menggunakan penyedia layanan berulang kali bahkan di masa depan sebagai kegiatan tindak lanjut dibuat setelah penggunaan selektif dari pelanggan". Strategi pemasaran yang harus diterapkan oleh perusahaan adalah menciptakan store atmosphere yang aman dan nyaman. [4] Store atmosphere adalah "suasana setiap cafe mempunyai tata letak fisik yang memudahkan konsumen". Setiap coffee shop harus berbeda baik itu dari segi penampilan maupun lainnya. Muaro Terrace juga harus menjaga pelayanan yang diberikan kepada konsumen. [5] Service quality "merupakan suatu kondisi yang berhubungan dengan produk, jasa, manusia, proses, dan lingkungan dimana penilaian kualitasnya ditentukan pada saat terjadinya pemberian pelayanan publik tersebut". Service quality atau kualitas pelayanan merupakan salah satu factor pembentuk kepuasan konsumen [6].

Dari hasil observasi awal yang dilakukan di Hotel Grand Inna Padang, terdapat permasalahan yang terlihat di Muaro Terrace tentang harga menu yang ditawarkan, menu Muaro Terrace coffee kurang bervariasi dan harga yang terlalu tinggi dibandingkan dengan coffee shop lainnya. Hal ini membuat para kalangan remaja yang telah berkunjung di Muaro Terrace coffee menjadi kurang berminat untuk melakukan revisit intention. Untuk desain exterior pada Muaro Terrace Coffee terlalu sempit jika tamu yang berkunjung ramai, sehingga membuat tamu merasa tidak nyaman dan pada sore hari tamu yang duduk di luar akan terkena matahari dan pada saat hujan akan basah. Kualitas pelayanan di Muaro Terrace Coffee juga dinilai kurang baik, terdapat beberapa tamu yang complain karena keterlambatan pengantaran pesanan tamu, sehingga tamu menunggu terlalu lama. Terdapat juga kesalahan pengantaran pesanan tamu, karena keteledoran waiter saat taking order.

\section{METODOLOGI}

Jenis penelitian tergolong pada penelitan asosiatif. [7] Penelitian asosiatif yaitu "Penelitian yang bertujuan untuk mengetahui pengaruh ataupun hubungan antara dua variabel atau lebih". Populasi yang digunakan adalah tamu yang pernah berunjung ke Muaro Terrace. Sampel yang digunakan 98 orang pengunjung. Pengumpulan data menggunakan kuisioner atau angket dengan lima pilihan jawaban yang telah melalui uji validitas dan reliabilitas. Uji prasyarat analisis yang digunakan yaitu normalitas, multikoloniaritas, heteroskedasitas. Pengujian hipotesis memakai uji regresi linier berganda, untuk melihat pengaruh dari variabel-variabel bebas terhadap variabel terikat yaitu revisit intention. 


\section{HASIL DAN PEMBAHASAN}

\section{A. HASIL PENELITIAN}

\section{Deskripsi Data Variabel}

Variabel Store Atmosphere sebanyak 21 item pernyataan. Hasil uji penelitian variabel Store Atmosphere pada konsumen yang berkunjung ke Muaro Terrace, sebagai berikut:

Tabel 1. Deskripsi Data Store Atmosphere

\begin{tabular}{cccc}
\hline Kategori & Kelas Interval & Frekuensi & $\mathbf{( \% )}$ \\
\hline Sangat Baik & $\geq \mathbf{8 4}$ & $\mathbf{8 1}$ & $\mathbf{8 2 , 7}$ \\
Baik & $70-<84$ & 17 & 17,3 \\
Kurang Baik & $56-<70$ & 0 & 0 \\
Buruk & $42-<56$ & 0 & 0 \\
Sangat Buruk & $<42$ & 0 & 0 \\
\hline & Total & $\mathbf{9 8}$ & $\mathbf{1 0 0}$ \\
\hline
\end{tabular}

Pada data diatas dapat diketahui bahwa variabel Store Atmosphere (X1) sebanyak 82,7\% responden tergolong sangat baik, $17,3 \%$ responden tergolong baik, $0 \%$ responden tergolong kurang baik, $0 \%$ responden tergolong buruk, dan $0 \%$ responden tergolong sangat buruk.

Variabel service quality terdiri dari 14 item pernyataan. Hasil penelitian variabel service quality pada konsumen yang berkunjung ke Muaro Terrace, sebagai berikut:

Tabel 2. Deskripsi Data Service Quality

\begin{tabular}{cccc}
\hline Kategori & Kelas Interval & Frekuensi & $\mathbf{( \% )}$ \\
\hline Sangat Baik & $\geq \mathbf{5 5 , 9 9}$ & $\mathbf{8 1}$ & $\mathbf{8 2 , 7}$ \\
Baik & $46,66-<55,99$ & 16 & 16,3 \\
Kurang Baik & $37,34-<46,66$ & 1 & 1 \\
Buruk & $28,01-<37,34$ & 0 & 0 \\
Sangat Buruk & $<28,01$ & 0 & 0 \\
\hline & Total & $\mathbf{9 8}$ & $\mathbf{1 0 0}$ \\
\hline
\end{tabular}

Dapat diketahui bahwa Service Quality (X2) sebanyak 82,7\% responden tergolong sangat baik, 16,3\% responden tergolong baik, $1 \%$ responden tergolong kurang baik, $0 \%$ responden tergolong buruk, dan $0 \%$ responden tergolong sangat buruk.

Variabel revisit intention terdiri dari 15 item pernyataan. Hasil penelitian variabel revisit intention pada konsumen yang berkunjung ke Muaro Terrace, sebagai berikut:

Tabel 3. Deskripsi Data Revisit Intention

\begin{tabular}{cccc}
\hline Kategori & Kelas Interval & Frekuensi & $\mathbf{( \% )}$ \\
\hline Sangat Baik & $\geq \mathbf{6 0}$ & $\mathbf{5 1}$ & $\mathbf{5 2}$ \\
Baik & $50-<60$ & 47 & 48 \\
Kurang Baik & $40-<50$ & 0 & 0 \\
Buruk & $30-<40$ & 0 & 0 \\
Sangat Buruk & $<30$ & 0 & 0 \\
\hline & Total & $\mathbf{9 8}$ & $\mathbf{1 0 0}$ \\
\hline
\end{tabular}

Dapat diketahui bahwa variabel Revisit Intention (Y) sebanyak 52\% responden tergolong sangat baik, $47 \%$ responden tergolong baik, $0 \%$ responden tergolong kurang baik, $0 \%$ responden tergolong buruk, dan $0 \%$ responden tergolong sangat buruk. 


\section{Uji Persyaratan Analisis}

\section{a. Uji Normalitas}

Tabel 4 UjiNormalitas.

One-Sample Kolmogorov-Smirnov Test

\begin{tabular}{|ll|r|r|r|}
\hline & & SA & KP & \multicolumn{1}{|c|}{ RI } \\
\hline N & & 98 & 98 & 98 \\
Normal Parameters ${ }^{\text {a,b }}$ & Mean & 89.3265 & 59.1020 & 59.7245 \\
& Std. Deviation & 6.36157 & 4.23410 & 6.41001 \\
& Absolute & .070 & .135 & .108 \\
Most Extreme Differences & Positive & .061 & .135 & .044 \\
& Negative & -.070 & -.094 & -.108 \\
Kolmogorov-Smirnov Z & & .698 & 1.333 & 1.072 \\
Asymp. Sig. (2-tailed) & & .715 & .057 & .201 \\
\hline
\end{tabular}

Diketahui nilai Asymp Sig untuk variabel Store Atmosphere adalah 0.715, Service Quality adalah 0.057 dan Revisit Intention adalah 0.201. Berdasarkan uji yang telah dilakukan, ketiga nilai tersebut $>$ dari 0,05 jadi ketiga nya dikatakan normal.

\section{b. Uji Multikolinearitas}

Tabel 5 Multikoliniaritas.

\begin{tabular}{|rl|r|c|}
\hline \multirow{2}{*}{ Model } & \multicolumn{2}{|c|}{ Collinearity Statistics } \\
\cline { 3 - 4 } & & Tolerance & \multicolumn{1}{c|}{ VIF } \\
\hline \multirow{2}{*}{1} & (Constant) & & \\
& StoreAtmospher & .597 & 1.675 \\
& KualitasPelayanan & .597 & 1.675 \\
\hline
\end{tabular}

Pada tabel diatas menunjukkan bahwa baik store atmosphere dan service quality terdapat nilai tolerance kecil dari 1 dan VIF terdapat nilai kecil dari 10 jadi disimpulkan tidak mengalami multikolinieritas.

\section{c. Uji Heterosdekastisitas}

Tabel 6. Uji Heterosdekastisitas Correlations

\begin{tabular}{|c|c|c|c|c|c|c|}
\hline & & & SA & $\mathrm{KP}$ & $\mathrm{RI}$ & $\begin{array}{l}\text { Unstandardiz } \\
\text { ed Residual }\end{array}$ \\
\hline \multirow{12}{*}{$\begin{array}{l}\text { Spearman's } \\
\text { rho }\end{array}$} & \multirow{3}{*}{ StoreAtmospher } & Correlation Coefficient & 1.000 & $.496^{\star \star}$ & $.431^{\star \star}$ & .021 \\
\hline & & Sig. (2-tailed) & & .000 & .000 & .840 \\
\hline & & $\mathrm{N}$ & 98 & 98 & 98 & 98 \\
\hline & \multirow{3}{*}{ KualitasPelayanan } & Correlation Coefficient & $.496^{* *}$ & 1.000 & $.422^{\star *}$ & -.006 \\
\hline & & Sig. (2-tailed) & .000 & & .000 & .952 \\
\hline & & $\mathrm{N}$ & 98 & 98 & 98 & 98 \\
\hline & \multirow{3}{*}{ RevisitIntention } & Correlation Coefficient & $.431^{\star \star}$ & $.422^{\star \star}$ & 1.000 & $.834^{\star \star}$ \\
\hline & & Sig. (2-tailed) & .000 & .000 & & .000 \\
\hline & & $\mathrm{N}$ & 98 & 98 & 98 & 98 \\
\hline & \multirow{3}{*}{$\begin{array}{l}\text { Unstandardized } \\
\text { Residual }\end{array}$} & Correlation Coefficient & .021 & -.006 & $.834^{* *}$ & 1.000 \\
\hline & & Sig. (2-tailed) & .840 & .952 & .000 & \\
\hline & & $\mathrm{N}$ & 98 & 98 & 98 & 98 \\
\hline
\end{tabular}

Berdasarkan hasil tabel diatas variabel store atmosphere, service quality dan revisit intention terdapat nilai sig besar daripada 0.05 maka tidak terjadi heteroskedastisitas. 


\section{Pengujian Hipotesis}

\section{Uji Regresi Linier Berganda}

Tabel 7. Nilai Signifikan

ANOVAa

\begin{tabular}{|rl|r|r|r|r|r|}
\hline Model & & Sum of Squares & Df & Mean Square & F & Sig. \\
\hline & Regression & 1175.417 & 2 & 587.708 & 19.868 & $.000^{\mathrm{b}}$ \\
\cline { 2 - 4 } & Residual & 2810.144 & 95 & 29.580 & & \\
& Total & 3985.561 & 97 & & & \\
\hline
\end{tabular}

a. Dependent Variable: RevisitIntention

b. Predictors: (Constant), KualitasPelayanan, StoreAtmospher

Hasil uji di atas terlihat $F$ hitung 19.868 dengan sign $0,000<0,05$ jadi model regresi dipakai. Artinya terjadi pengaruh yang signifikan pada ketiga variable. Untuk mengetahui besar koefisien regresi pada $\left(\mathrm{X}_{1}\right)$ dan $\left(\mathrm{X}_{2}\right)$ terhadap $(\mathrm{Y})$, terlihat pada hasil berikut :

Tabel 8. Koefesien

Coefficients $^{a}$

\begin{tabular}{|c|c|c|c|c|c|c|}
\hline \multirow{2}{*}{\multicolumn{2}{|c|}{ Model }} & \multicolumn{2}{|c|}{ Unstandardized Coefficients } & \multirow{2}{*}{$\begin{array}{c}\begin{array}{c}\text { Standardized } \\
\text { Coefficients }\end{array} \\
\text { Beta }\end{array}$} & \multirow[t]{2}{*}{$\mathrm{T}$} & \multirow[t]{2}{*}{ Sig. } \\
\hline & & $\mathrm{B}$ & Std. Error & & & \\
\hline \multirow{3}{*}{1} & (Constant) & 5.931 & 8.569 & & .692 & .491 \\
\hline & StoreAtmospher & .265 & .112 & .263 & 2.360 & .020 \\
\hline & KualitasPelayanan & .510 & .169 & .337 & 3.018 & .003 \\
\hline
\end{tabular}

a. Dependent Variable: RevisitIntention

Pada tabel 8 tersebut didapatkan persamaan regresi yaitu :

$$
\begin{gathered}
\mathbf{Y =} \mathbf{a}+\mathbf{b} \mathbf{X}_{1}+\mathbf{b} \mathbf{X}_{2} \\
Y=5.931+0,265 X 1+0,510 X 2
\end{gathered}
$$

Pada persamaan regresi terlihat konstanta (intersept) sebesar 5.931 ini berarti store atmosphere dan service quality tidak berubah, maka rata-rata revisit intention akan bernilai sebesar 5.931 persen. Untuk melihat terjadinya pengaruh, sebagai berikut :

Tabel 9.

Model Summary

\begin{tabular}{|l|r|r|r|r|}
\hline Model & $R$ & $R$ Square & \multicolumn{1}{|c|}{$\begin{array}{c}\text { Adjusted R } \\
\text { Square }\end{array}$} & $\begin{array}{l}\text { Std. Error of the } \\
\text { Estimate }\end{array}$ \\
\hline 1 & $.543^{\mathrm{a}}$ & .295 & .280 & 5.439 \\
\hline
\end{tabular}
a. Predictors: (Constant), KualitasPelayanan, StoreAtmospher
b. Dependent Variable: RevisitIntention

Hasil diatas, terlihat nilai $\mathrm{R}$ Square 0,295 ini berarti pengaruh variabel $\left(\mathrm{X}_{1}\right.$ dan $\left.\mathrm{X}_{2}\right)$ terhadap variabel (Y) adalah sebanyak $28 \%$. dan sebanyak $72 \%$ dipengaruhi oleh faktor lain. 


\section{B. Pembahasan}

Dari hasil, maka dapat dipaparkan pembahasan terkait Store Atmosphere, Service Quality dan Revisit Intention serta pengaruh nya. Berdasarkan hasil pengolahan data dari 98 sampe, Store Atmosphere dilihat dari 4 indikator yaitu : Exterior 78,6\% responden sangat baik, pada indikator General Interior 74,5\% responden sangat baik, pada indikator Store Layout 94,9\% responden sangat baik dan yang terakhir indikator Interior Point Of Purchase 82,7\% responden sangat baik. Jadi berdasarkan penjelasan diatas variable Store Atmosphere di Muaro Terrace berada kategori sangat baik. [8] Atmosper mengacu terhadap suasana yang dirasakan oleh tamu yang membuat tamu merasa tentram serta bahagia saat berada di tempat tersebut. Oleh karena itu pihak manajemen Muaro Terrace harus mampu mempertahankan kualitas tampilan bagian luar toko, dari segi tata letak, pencahaayaan, musik dan aroma agar konsumen merasa puas. Kepuasan yang didapat konsumen akan membuat konsumen ingin datang Kembali [9].

Berdasarkan hasil pengolahan data dari 98 sampel, Service quality dilihat dari 4 indikator yaitu : Tangible 94,9\% responden tergolong sangat baik, pada indikator Reliability 92,9\% responden tergolong sangat baik, pada indikator Responsiveness $73,5 \%$ responden mengatakan sangat baik dan yang terakhir indikator Assurance 68,4\% responden sangat baik. Jadi berdasarkan penjelasan diatas variable Service Quality di Muaro Terrace berada kategori sangat baik. [10] "kualitas pelayanan adalah penilaian keseuaian antara produk maupun jasa dengan kualitas yang telah diberikankan”. Oleh karena itu pihak manajemen Muaro Terrace harus mampu mempertahankan pelayanan kepada konsumen agar konsumen merasa senang saat berada di Muaro Terrace.

Berdasarkan hasil pengolahan data dari 98 sampel, Revisit Intention dilihat dari 4 indikator yaitu : menjadi tempat prioritas minum kopi 69,4\% responden sangat baik, pada indikator mencari informasi terbaru mengenai tempat tersebut $54,1 \%$ responden sangat baik, pada indikator bersedia menceritakan pengalaman $77,5 \%$ responden sangat baik dan yang terakhir indikator mengatakan hal-hal positif $64,3 \%$ responden sangat baik. Jadi berdasarkan penjelasan diatas variable Revisit Intention di Muaro Terrace berada kategori sangat baik, adanya penelitian ini diharapkan agar menjadi gambaran bagi manajemen Muaro Terrace untuk tetap mempertahankan dan menjaga kenyamanan konsumen agar konsumen melakukan kunjungan kembali ke Muaro Terrace [11]. Oleh karena itu pihak manajemen Muaro Terrace harus mampu mempertahankan kenyamanan konsumen agar konsumen melakukan kunjungan kembali ke Muaro Terrace. Hasil uji hipotesis diperoleh $\mathrm{F}$ hitung 19,868 dengan sign 0,000 < 0,05 maka diperoleh Ha. Hasil R square menunjukan jika Store Atmosphere dan Service Quality memiliki kontribusi sebesar 28\% dan sisanya sebanyak $72 \%$ merupakan kontribusi pengaruh dari faktor-faktor lain. Faktor-faktor tersebut dapat berupa faktor-faktor seperti fasilitas [12], kualitas produk, harga, dan factor lain yang dapat memuaskan pengunjung dan berdampak pada niat konsumen untuk dating Kembali. 


\section{KESIMPULAN}

Berdasarkan hasil penelitian yang telah dilakukan, maka dapat di ambil kesimpulan dari penelitian ini :

1. Variabel X1 (Store Atmosphere) dari indikator yang telah ditentukan menunjukan secara keseluruhan dengan nilai persentase sebesar $82,7 \%$ berada pada $\geq 84$ termasuk kategori sangat baik.

2. Variabel X2 (Service Quality) dari indikator yang telah ditentukan menunjukan secara keseluruhan dengan nilai persentase sebesar $82,7 \%$ berada pada $\geq 55,99$ termasuk kategori sangat baik.

3. Variabel Y (Revisit Intention) dari indikator yang telah ditentukan menunjukan secara keseluruhan dengan nilai persentase sebesar $52 \%$ berada pada $\geq 60$ termasuk kategori sangat baik.

4. Terjadi pengaruh signifikan $X_{1}$ dan $X_{2}$ terhadap $Y$ konsumen di Muaro Terrace sebesar 29,5\% sedangan $70,5 \%$ ditentukan oleh faktor lain. 


\section{DAFTAR PUSTAKA}

[1] Budi, Menejemen marketing perhotelan. Yogyakarta: CV. Andi, 2013.

[2] K. Ahmad, "Pengaruh Promosi terhadap Keputusan Pembelian Konsumen pada Nichol Coffee," Manaj. Ekon. dan Bisnis, vol. 1, 2016.

[3] H. Jeon, "The Effect of Experiential Marketing on Customer Satisfaction and Revisit Intention of Beauty Salon Franchise Stores," Fash. Bus., vol. 17, no. 3, pp. 109-121, 2013, doi: 10.12940/jfb.2013.17.3.109.

[4] P. Kotler and K. L. Keller, MarkKotler, P., \& Keller, K. L. (2016). Marketing Management. Global Edition (Vol. 15E). https://doi.org/10.1080/08911760903022556eting Management, vol. 15E, no. 4. 2016.

[5] Hardiansyah, "Kualitas Pelayanan Publik Konsep Dimensi Indikator dan Implementasinya," Gava Media, 2018.

[6] L. Eva and K. Kasmita, "Pengaruh Service Quality Terhadap Kepuasan Tamu Menginap di UNP Hotel \& Convention," J. Kaji. PARIWISATA DAN BISNIS PERHOTELAN, vol. 2, no. 1, pp. 59-66, 2021, doi: https://doi.org/10.24036/jkpbp.v2i1.26072.

[7] Sugiyono., Metode Penelitian Kuantitatif, Kualitatif dan R\&D. Bandung: Alfabeta, 2016.

[8] L. dan Weitz, "Retailing Management Information Center," in Mc Graw Hill Higher Education, New York, 2012.

[9] Suci Sandi Wachyuni1 and K. Wiweka2, "KEPUASAN WISATAWAN DALAM PENGGUNAAN E-COMMERCE AGODA DALAM PEMESANAN HOTEL," J. Tour. Destin. attraktion, vol. 8, no. 1, pp. 61-70, 2020, doi: https://doi.org/10.35814/tourism.v8i1.1366.

[10] F. Tjiptono and G. Chandra, "Service, Quality \& Satisfaction," in Edisi 4, 2011.

[11] A. P. M. dkk. Som, "Factors Influencing Visitors' Revisit. Behavioral Intentions: A Case Study of Sabah, Malaysia, International.," Int. J. Mark. Stud., vol. 4, no. 39-50, 2012.

[12] A. Wedi and Y. Abrian, "Pengaruh Fasilitas Terhadap Kepuasan Tamu Menginap Di Hannah Hotel Syariah Painan," J. Pendidik. Dan Kel., vol. 11, no. 1, p. 68, 2019, doi: 10.24036/jpk/vol11-iss1/582. 